\title{
The Effectiveness of the 'One-Table One-Flower' Program on Job Stress Management of Police Officials
}

\author{
Hye Jung Choi ${ }^{1}$, Suk Young Yun ${ }^{2 *}$, Sang Woon Kim ${ }^{3}$, and Su Young Sung ${ }^{4}$ \\ ${ }^{1}$ Doctoral student, Department of Horticulture, Daegu Catholic University, Gyeongsan 38430, Korea \\ ${ }^{2}$ Professor, Department of Horticulture, Daegu Catholic University, Gyeongsan 38430, Korea \\ ${ }^{3}$ Professor, Department of Police Administration, Daegu Catholic University, Gyeongsan 38430, Korea \\ ${ }^{4}$ Inspector, Daegu Dongbu Police Station, Daegu 41074, Korea
}

\section{ABSTRACT}

The purpose of this study was to determine the effects of flower decorations on job stress and stress copying style of police officers. Flower decorations were done in the form of "one-table one-flower", in which flowers were placed on each desk in the office space. By analyzing color psychology, we first identified the symbolism of color, and selected the cut flowers in the same color. We selected six types of flowers in six colors: red, orange, yellow, green, blue and purple. Each Monday morning, the flower decorations were delivered to the police station. We selected 50 subjects who wanted to keep flowers on their desks every week as the experimental group and 44 subjects who only wanted to participated in the assessment as the control group. Before and after the program, we examined the mean difference between the control group and experimental group. After six sessions of the program, there was a significant difference in job stress $(p<.001)$ and stress copying style $(p=.049)$ of the experimental group compared to the control group. Therefore, this study proved that having flower decorations in an office space is effective for the psychological stability of police officers that are highly stressed, due to sensory stimulations from the colors and scents of flowers as well as mutual interaction as they take care of the flowers.

Keywords: color psychology, flower decoration, office space, psychological stability

\section{Introduction}

As the scope of duties for the police broadened along with the advancement of science and technology as well as the increasing diversity of the society, police officers are facing heavier workloads, such as the 112 notification system that requires the police to 'arrive on site within 5 minutes' anytime and anywhere, and the reduced deadline for handling charges and accusations. Job stress of police officers in crises or emergencies leads to decreased motivation to work, thereby causing a problem in the national public security service (Jeong and Yoon, 2014).

Police officers suffer more from stress than others, and the more they are stressed, the more they tended to show deviant behaviors (Arter, 2007). This also hindered job satisfaction and organizational commitment, ultimately causing difficulty in effective handling of crimes and making police officers disregard or show hostility toward citizens they must protect (Moon, 2011). In particular, an analysis on the level of job stress and factors that cause such stress for police officers in Daegu proved that factors such as physical fatigue, psychological tension or anxiousness, and lack of concentration showed high levels in regard to stress. Moreover, physical and environmental factors such as personnel management, working overtime, obsolete devices, office design, lighting and noise appeared to cause stress (Kim et al., 2002).

Without proper management of job stress for police offi-

Received: October 9, 2019, Revised: November 15, 2019, Accepted: January 30, 2020

First author: Hye Jung Choi, liloo71@naver.com, (1) https://orcid.org/0000-0001-5086-4518

*Corresponding author: Suk Young Yun, yune1004@cu.ac.kr, (D) https://orcid.org/0000-0002-5862-0021 
cers, individuals, organizations and citizens will suffer damage as a negative result. Advanced countries are actively conducting research on stress of police officers due to the importance of their job stress, and are implementing and operating institutional systems to relieve their stress. Meanwhile, there are studies on job stress of police officers in Korea as well, but they lack diversity (Yoo, 2014). It is necessary to provide suitable contents for users using their biosignals and psychological information to increase the effect of stress relief (Kim and Kim, 2011).

It is important to stimulate humans to have a positive mindset that they can do something in life, and horticulture easily provides such environment (Kim, 2003), and the stable environment of nature has begun to be used therapeutically, anticipated to bring mental stability to those participating in horticultural activities (Simson and Straus, 1997). Stress is much less perceived when one is exposed to a natural environment with many nature-related elements than an urban environment (Ulrich, 1981), and therapy that stimulates the five senses with plants is effective for people with mental disabilities (Cho et al., 2003). Horticultural activities are different from other therapies in terms of their effect as they are carried out using many sensory organs by seeing with the eyes, smelling with the nose, touching with the hands, and thinking and moving (Son, 1997).

There is a research proving that floral design is effective in increasing stability and relieving stress of participants (Tak, 2006). Floral design not only provided emotional stability but also helped relieve stress with actions such as trimming, cutting, bending, arranging, knotting and twisting flowers (Jeong and Han, 2008). After making floral arrangement using flowers with various shapes, colors and scents, there were positive changes to emotional balance and decrease in depression of inpatient elderly (Yun et al., 2009). Moreover, as a result of giving stress to mice with electrostimulation as a passive effect of horticultural activities and measuring the cortisol level, which is a stress hormone, with the treatment of cut flowers and fragrance of essential oil, a significant effect was found in cut white trumpet lilies and rose essential oil (Kim et al., 2006). In addition, studies that determined the physiological and psychological effectiveness of roses proved that office workers showed a significant increase in parasympathetic activities when they observed roses compared to the control group and also reported that they felt much more relaxed in subjective assessment (Ikei et al., 2014). Olfactory stimulation of fresh roses also increased parasympathetic activities as well as a relaxing, natural feeling (Igarashi et al., 2014).

According to the Yin-Yang and the Five Elements theory that is the basis of Eastern medicine, the energy ("qi") of the colors, scents and shapes of flowers is combined with the energy of humans to heal people, and plants have distinctive effects depending on their type (Katakiri, 1996). Colors of flowers also induce psychological change in humans, showing effects of color therapy. Color sensation obtained with panesthesia has a remarkable effect on determining or perceiving human behavior with consciously and unconsciously stored memory or experience (Kim, 2013).

Therefore, this study presented flowers decorated by color every Monday morning to police officers working at a police station, and had them work closely with the flowers on their desks, smell them, and experience the act of caring by watering them. In other words, we intended to examine the decrease in job stress and changes in the stress coping style through the experience of "one-table one-flower".

\section{Research Methods}

\section{Subjects}

This study is conducted on police officers working at D Police Station located in D Metropolitan City. We first extracted 100 subjects with random sampling, and then extracted 94 of them who expressed the will to participate in the study after explaining the purpose. We selected 50 subjects who wanted to keep flowers on their desks every week as the experimental group and 44 subjects who only wanted to participated in the assessment as the control group.

\section{Tools}

\section{Program design}

Flower decorations were done in the form of "one-table one-flower" in which the subjects placed flowers on each of their desks in the office space. First, we divided and 
analyzed the symbolic meaning of colors applied to color psychology into general symbol and psychological symbol, and selected red, orange, yellow, green, blue and purple as colors related to positive emotional responses, especially stress (Kim, 2013). Next, to select the cut flowers in the same colors as the ones selected by symbolism, we used a portable color reading tool (Pantone Capsure X-rite Model RM 200, Pantone LLC, 2010) and identified the accurate colors of cut flowers distributed in the market with Pantone color libraries by applying it to the surface of petals. Table 1 shows the colors of cut flowers selected in each session and their symbolic meanings.

First, in Session 1, we selected red 'Dianthus caryophyllus' that symbolizes life, passion, enterprising, energy, vigor and ambition for Parents' Day, and wrapped up the flowers and placed them on the desks. In Session 2, we selected orange 'Rosa hybrida' that symbolizes festival, activity, fullness and curiosity. In Session 3, we selected yellow 'Helianthus annuus' that symbolizes light, brightness, intelligence, positive and optimistic attitude. In Session 4, we provided a positive meaning by selecting green 'Eustoma grandiflorum' that symbolizes nature, abundance, hope, peace and reconciliation. In Session 5, we selected blue 'Oxypetalum caeruleum' that symbolizes water, heaven, healing, truth and eternity and has the psychological effects of relieving insomnia and increasing clarity and creativity. In Session 6, we selected purple
'Limonium sinuatum' that symbolizes strength, love, patience, humility and sublimation to feel the psychological effects of color that relieves anxiety and protects the mind.

\section{Implementation}

This study was conducted in total six sessions, one session a week, from May 6 to June 10, 2019. Every Monday morning, flowers decorated in each of the selected colors are delivered to the experimental group and placed on individual desks. Flowers were decorated by the researcher (State Registered Engineer Floral Design license holder) using the selected cut flowers, arranging them in four directions of the floral foam $(10 \times 10 \times 10 \mathrm{~cm})$. Then the floral foam was wrapped in wrapping paper that is in a color similar to that of the flower, and safely arranged so that the water does not leak on the office desk. The experimental group was to water the flowers every other day to experience "one table one flower". To reduce job stress and improve stress coping style of police officers, the flowers were delivered each session along with the symbolic meanings of colors and floral language of the flowers (Fig. 1).

\section{Assessment tools}

(1) Job stress

This study used the Police Stress Survey (PSS) developed by Spielberger et al. (1981), which was revised and modified by Kim (2014) to be more adequate for Korea,

Table 1. Colors and symbolic meanings of cut flowers used in 'one-table one-flower' program

\begin{tabular}{|c|c|c|c|c|c|c|}
\hline Session & Date & Color & Symbol & Symbolic meaning of color & Cut flower & $\begin{array}{l}\text { Pantone } \\
\text { color }\end{array}$ \\
\hline \multirow{2}{*}{1} & \multirow{2}{*}{ May 7} & \multirow{2}{*}{ Red } & General & Life, passion, enterprising, energy & \multirow{2}{*}{$\begin{array}{c}\text { Dianthus } \\
\text { caryophyllus }\end{array}$} & \multirow{2}{*}{$\begin{array}{l}\text { Pantone } \\
19-1758\end{array}$} \\
\hline & & & Psychological & Overcoming negative thinking, bringing vigor and ambition & & \\
\hline \multirow{2}{*}{2} & \multirow{2}{*}{ May 13} & \multirow{2}{*}{ Orange } & General & Festival, activity, fullness, curiosity & \multirow{2}{*}{ Rosa hybrida } & \multirow{2}{*}{$\begin{array}{l}\text { Pantone } \\
17-1360\end{array}$} \\
\hline & & & Psychological & Prevents malfunction and frees up emotions & & \\
\hline \multirow{2}{*}{3} & \multirow{2}{*}{ May 20} & \multirow{2}{*}{ Yellow } & General & Light, bright, intelligence, positive & \multirow{2}{*}{$\begin{array}{c}\text { Helianthus } \\
\text { annuus }\end{array}$} & \multirow{2}{*}{$\begin{array}{c}\text { Pantone } \\
1215 \mathrm{U}\end{array}$} \\
\hline & & & Psychological & Confidence, optimism, new ideas & & \\
\hline \multirow{2}{*}{4} & \multirow{2}{*}{ May 27} & \multirow{2}{*}{ Green } & General & Nature, abundance, hope, peace, reconciliation & \multirow{2}{*}{$\begin{array}{c}\text { Eustoma } \\
\text { grandiflorum }\end{array}$} & \multirow{2}{*}{$\begin{array}{c}\text { Pantone } \\
\text { P163-15U }\end{array}$} \\
\hline & & & Psychological & Calm and balanced roles of stress and intense emotions & & \\
\hline \multirow{2}{*}{5} & \multirow{2}{*}{ June 3} & \multirow{2}{*}{ Blue } & General & Water, heaven, healing, truth, eternity & \multirow{2}{*}{$\begin{array}{l}\text { Oxypetalum } \\
\text { caeruleum }\end{array}$} & \multirow{2}{*}{$\begin{array}{l}\text { Pantone } \\
82-3-5 C\end{array}$} \\
\hline & & & Psychological & Insomnia relief, increased clarity, creativity & & \\
\hline \multirow{2}{*}{6} & \multirow{2}{*}{ June 10} & \multirow{2}{*}{ Purple } & General & Strength, love, patience, humility, sublimation & \multirow{2}{*}{$\begin{array}{l}\text { Limonium } \\
\text { sinuatum }\end{array}$} & \multirow{2}{*}{$\begin{array}{l}\text { Pantone } \\
\text { P96-16C }\end{array}$} \\
\hline & & & Psychological & Relieves shock or fear, purifies anxiety, protects & & \\
\hline
\end{tabular}




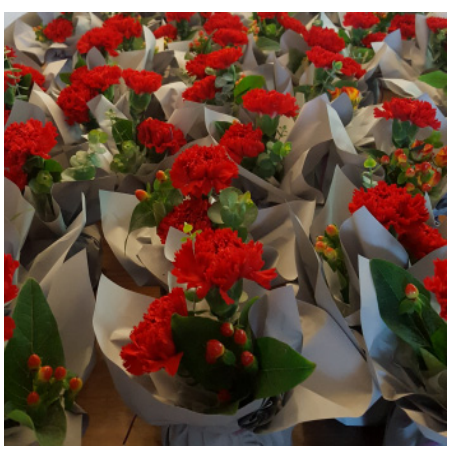

Session 1; red color

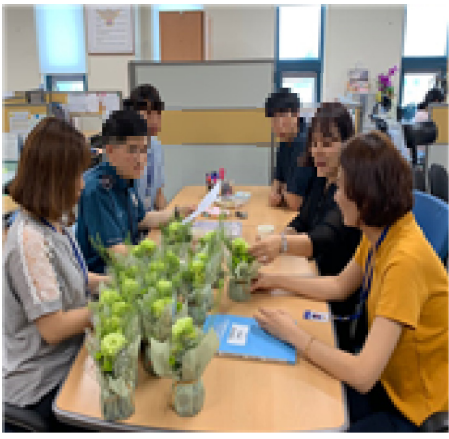

Session 4; green color

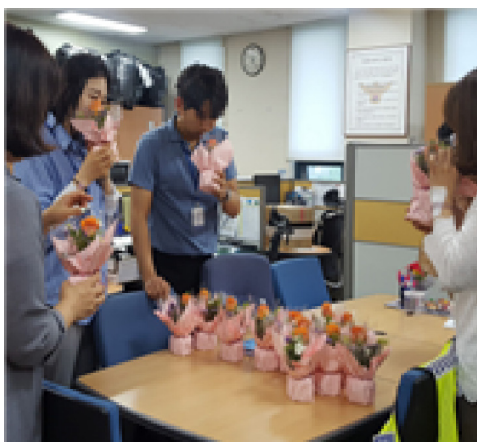

Session 2; orange color

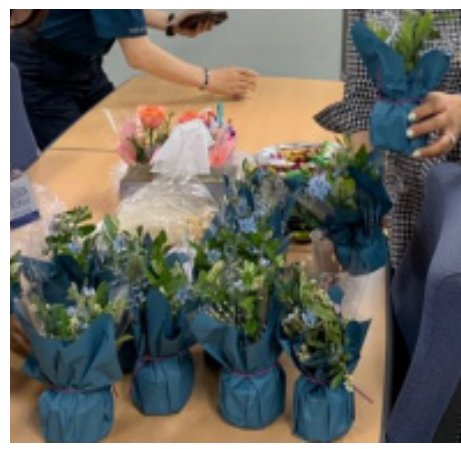

Session 5; blue color

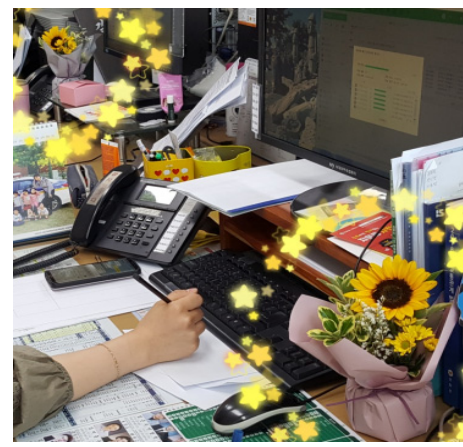

Session 3; yellow color

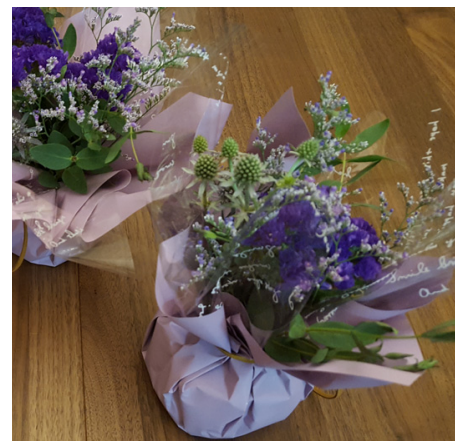

Session 6; purple color

Fig. 1. Color scheme of each session of 'one-table one-flower' program and activity images.

and measured job stress of police officers with the ultimately selected 27 items with self-measurement before and after the program. The items were rated on a 5-point scale of 'Don't feel at all (1 point), Don't feel much (2 points), Neutral (3 points), Feel much in general (4 points), and Feel very much (5 points)', and job stress was measured by adding up the scores of the responses for subitems. Job stress is distributed throughout the range of 27 points minimum to 135 points maximum. The reliability was Cronbach's $\alpha=.917$ in the previous study by Kim (2014) that used the same items, and in this study it was Cronbanch's $\alpha=.943$.

\section{(2) Stress coping style}

This study used the scale developed by Folkman \& Lazarus (1985), on which Gong and Lee (2006) conducted a confirmatory factor analysis and ultimately selected 16 items, and had the subjects self-measure their stress coping style before and after the experiment. There were nine items for problem-focused coping and seven items for emotion-focused coping, and the subjects were to rate the extent in which they use the stress coping style as "Not at all 1 , Not really 2, Somewhat 3, In general 4, and Always 5 ". The scores of the subitems are added, and higher scores indicate that the relevant coping style is frequently used. The reliability in this study was Cronbanch's $\alpha=.765$.

\section{Data analysis}

The collected data was analyzed using the SPSS (version 19.0, IBM, USA, 2012) program. Reliability analysis was first conducted to examine the internal consistency of the self-report questionnaire, and the normality of the collected data was tested using the one-sample Kolmogorov-Smirnov test. The collected data of job stress was $p=.585$ and that of stress coping style was $p=.490$, both following normal distribution, and thus the preliminary test of homogeneity of the control group and experimental group as well as the comparison of the two groups after the experiment was analyzed using an independent samples t-test. The subjects were classified by gender, age and rank, using a paired sample t-test to compare the means before and after the experiment. The significance level was set at $p<.05$. 


\section{Results and Discussion}

\section{General characteristics}

Total 94 subjects (44 in the control group and 50 in the experimental group) participated in this study to examine the decrease in job stress and change in stress coping style of police officers through the experience of "one-table one-flower". General characteristics of the subjects are as follows; $73.4 \%$ were male and $26.6 \%$ were female, $6.4 \%$ were in their $20 \mathrm{~s}, 27.6 \%$ in their $30 \mathrm{~s}, 36.2 \%$ in their $40 \mathrm{~s}$, and $29.8 \%$ in their $50 \mathrm{~s}, 84.0 \%$ were married and $16.0 \%$ were unmarried, $16.0 \%$ had work experience of 5 years or less, $11.7 \%$ had 5-10 years of experience, $22.3 \%$ had $10-15$ years, $16.0 \%$ had $15-20$ years, and $34.0 \%$ had more than 20 years of experience. By police rank, 9.6\% were constables, $14.9 \%$ were corporals, $20.2 \%$ were sergeants, $41.5 \%$ were lieutenants, $12.7 \%$ were inspectors, and $1.1 \%$ were superintendents (Table 2).

\section{Preliminary test of homogeneity}

We analyzed the measures of job stress and coping style with an independent t-test to determine the homogeneity of the two groups. The mean of job stress was 86.9 points $(\mathrm{SD}=12.8)$ for the control group and $81.2(\mathrm{SD}=17.7)$ for the experimental group, showing no statistically significant difference $(p=.081)$. The mean of coping style was $51.0(\mathrm{SD}=6.1)$ for the control group and $51.2(\mathrm{SD}=5.8)$ for the experimental group, showing no statistically significant difference ( $p=.841$; Table 3$)$. Therefore, the two groups were regarded as homogeneous groups, and thus the comparative experiment could be conducted.

\section{Effects of the "one-table one-flower" program}

The experimental group was to participate in the "one-table one-flower" program for 6 weeks. After the program, job stress was 92.1 points $(\mathrm{SD}=12.8)$ for the control group but $75.3(\mathrm{SD}=15.1)$ for the experimental group, showing a highly significant difference $(p<.001)$, and coping

Table 2. General characteristics of study subjects

\begin{tabular}{|c|c|c|c|c|}
\hline \multirow{2}{*}{ Characteristics } & \multirow{2}{*}{ Sort } & \multicolumn{3}{|c|}{ Frequency $(\%)$} \\
\hline & & Total & Control $(n=44)$ & Experimental $(\mathrm{n}=50)$ \\
\hline \multirow{2}{*}{ Gender } & Male & $69(73.4)$ & $38(40.4)$ & $31(33.0)$ \\
\hline & Female & $25(26.6)$ & $6(6.4)$ & $19(20.2)$ \\
\hline \multirow{4}{*}{ Age } & $20 \mathrm{~s}$ & $6(6.4)$ & $3(3.2)$ & $3(3.2)$ \\
\hline & $30 \mathrm{~s}$ & $26(27.6)$ & 13 (13.8) & 13 (13.8) \\
\hline & $40 \mathrm{~s}$ & $34(36.2)$ & $15(16.0)$ & $19(20.2)$ \\
\hline & $50 \mathrm{~s}$ & $28(29.8)$ & $13(13.8)$ & $15(16.0)$ \\
\hline \multirow{2}{*}{ Marital status } & Married & $79(84.0)$ & $38(40.4)$ & $41(43.6)$ \\
\hline & Unmarried & $15(16.0)$ & $6(6.4)$ & $9(9.6)$ \\
\hline \multirow{5}{*}{ Years of work experience } & 5 years or less & $15(16.0)$ & $6(6.4)$ & $9(9.6)$ \\
\hline & $5-10$ years & 11 (11.7) & $7(7.4)$ & $4(4.3)$ \\
\hline & $10-15$ years & $21(22.3)$ & $8(8.5)$ & 13 (13.8) \\
\hline & $15-20$ years & $15(16.0)$ & $8(8.5)$ & $7(7.4)$ \\
\hline & More than 20 years & $32(34.0)$ & $15(16.0)$ & $17(18.1)$ \\
\hline \multirow{6}{*}{ Police rank } & Constable & $9(9.6)$ & $4(4.3)$ & $5(5.3)$ \\
\hline & Corporal & $14(14.9)$ & $4(4.3)$ & $10(10.6)$ \\
\hline & Sergeant & $19(20.2)$ & $11(11.7)$ & $8(8.5)$ \\
\hline & Lieutenant & $39(41.5)$ & $20(21.3)$ & $19(20.2)$ \\
\hline & Inspector & 12 (12.7) & $5(5.3)$ & 7 (7.4) \\
\hline & Superintendent & $1(1.1)$ & $0(0)$ & $1(1.1)$ \\
\hline
\end{tabular}


Table 3. Mean difference verification between control and experimental group before conducting the program

\begin{tabular}{|c|c|c|c|c|c|}
\hline \multirow{2}{*}{ Item } & \multicolumn{2}{|c|}{ Control } & \multicolumn{2}{|c|}{ Experimental } & \multirow{2}{*}{$p$} \\
\hline & M & SD & M & $\mathrm{SD}$ & \\
\hline Job stress (score) & 86.9 & 12.8 & 81.2 & 17.7 & $.081^{\mathrm{NS}}$ \\
\hline Coping style (score) & 51.0 & 6.1 & 51.2 & 5.8 & $.841^{\mathrm{NS}}$ \\
\hline
\end{tabular}

${ }^{\mathrm{NS}}$ Non-significant by independent t-test.

Table 4. Mean difference verification between the control and experimental group after conducting the program

\begin{tabular}{|c|c|c|c|c|c|}
\hline \multirow{2}{*}{ Item } & \multicolumn{2}{|c|}{ Control } & \multicolumn{2}{|c|}{ Experimental } & \multirow{2}{*}{$p$} \\
\hline & M & $\mathrm{SD}$ & M & $\mathrm{SD}$ & \\
\hline Job stress (score) & 92.1 & 12.8 & 75.3 & 15.1 & $<.001^{* * *}$ \\
\hline Coping style (score) & 51.0 & 5.1 & 52.4 & 6.0 & $.049^{*}$ \\
\hline
\end{tabular}

${ }^{*} p<.05, \stackrel{* * *}{p} p<.001$ by independent t-test.

Table 5. Changes in the level of job stress and coping style before and after program by gender

\begin{tabular}{|c|c|c|c|c|c|c|c|}
\hline \multirow{2}{*}{ Item } & \multirow{2}{*}{ Group } & \multirow{2}{*}{ Gender } & \multicolumn{2}{|c|}{ Before } & \multicolumn{2}{|c|}{ After } & \multirow{2}{*}{$p$} \\
\hline & & & $\mathrm{M}$ & SD & $M$ & SD & \\
\hline \multirow{4}{*}{$\begin{array}{c}\text { Job stress } \\
\text { (score) }\end{array}$} & \multirow{2}{*}{ Control } & Male & 88.1 & 12.9 & 93.4 & 12.7 & $.010^{*}$ \\
\hline & & Female & 79.3 & 9.5 & 83.3 & 10.6 & .210 \\
\hline & \multirow{2}{*}{ Experimental } & Male & 81.6 & 16.5 & 76.9 & 14.0 & $.003^{* *}$ \\
\hline & & Female & 72.6 & 16.8 & 72.6 & 16.8 & .065 \\
\hline \multirow{4}{*}{$\begin{array}{l}\text { Coping style } \\
\text { (score) }\end{array}$} & \multirow{2}{*}{ Control } & Male & 51.5 & 6.3 & 50.1 & 5.4 & $.018^{*}$ \\
\hline & & Female & 48.5 & 3.4 & 49.5 & 3.2 & .562 \\
\hline & \multirow{2}{*}{ Experimental } & Male & 50.9 & 6.3 & 51.3 & 5.9 & .533 \\
\hline & & Female & 51.7 & 4.9 & 54.1 & 5.8 & .072 \\
\hline
\end{tabular}

${ }^{*} p<.05,{ }^{* *} p<.01$ by paired t-test.

style was $51.0(\mathrm{SD}=5.1)$ for the control group but 52.4 $(\mathrm{SD}=6.0)$ for the experimental group, showing a significant difference $(p=.049$; Table 4$)$.

\section{Comparison by characteristics of subjects}

\section{Changes by gender}

We classified the means before Session 1 and after Session 6 into male and female. As for job stress in the control group, men showed a significant increase from 88.1 $(\mathrm{SD}=12.9)$ to $93.4(\mathrm{SD}=12.7 ; p=.010)$, whereas women did not show a significant difference from $79.3(\mathrm{SD}=9.5)$ to 83.3 ( $\mathrm{SD}=10.6 ; p=.210$ ). On the other hand, in the experimental group, men showed a significant decrease from $81.6(\mathrm{SD}=16.5)$ to $76.9(\mathrm{SD}=14.0 ; p=.003)$, whereas women did not show a significant change from
$72.6(\mathrm{SD}=16.8)$ to $72.6(\mathrm{SD}=16.8 ; p=.065)$. For stress coping style in the control group, men did not show a significant change from $51.5(\mathrm{SD}=6.3)$ to 50.1 ( $\mathrm{SD}=5.4$; $p=.018)$, and neither did women from $48.5 \pm 3.4$ to 49.5 $(\mathrm{SD}=3.2 ; p=.562)$. In the experimental group, men showed a slight increase from $50.9(\mathrm{SD}=6.3)$ to 51.3 $(\mathrm{SD}=5.9 ; p=.533)$, and women from $51.7(\mathrm{SD}=4.9)$ to 54.1 ( $\mathrm{SD}=5.8 ; p=.072$ ), but both genders did not show significance. In other words, only men in the experimental group showed a significant effect in job stress, while there was not much difference in other cases depending on gender (Table 5).

\section{Changes by age}

We classified the means before Session 1 and after Session 6 by age. As for job stress in the control group, 20s showed 
Table 6. Changes in the level of job stress and coping style before and after program by age

\begin{tabular}{|c|c|c|c|c|c|c|c|}
\hline \multirow{2}{*}{ Item } & \multirow{2}{*}{ Group } & \multirow{2}{*}{ Age } & \multicolumn{2}{|c|}{ Before } & \multicolumn{2}{|c|}{ After } & \multirow{2}{*}{$p$} \\
\hline & & & $M$ & $\mathrm{SD}$ & $M$ & SD & \\
\hline \multirow{8}{*}{$\begin{array}{c}\text { Job stress } \\
\text { (score) }\end{array}$} & \multirow{4}{*}{ Control } & $20 \mathrm{~s}$ & 80.0 & 14.7 & 80.7 & 14.3 & .184 \\
\hline & & $30 \mathrm{~s}$ & 82.6 & 12.1 & 90.5 & 7.5 & $.016^{*}$ \\
\hline & & $40 \mathrm{~s}$ & 90.9 & 10.2 & 97.8 & 12.3 & $.022^{*}$ \\
\hline & & $50 \mathrm{~s}$ & 88.1 & 15.1 & 89.7 & 15.4 & .703 \\
\hline & \multirow{4}{*}{ Experimental } & $20 \mathrm{~s}$ & 75.0 & 2.6 & 62.7 & 6.7 & .129 \\
\hline & & $30 \mathrm{~s}$ & 87.2 & 15.1 & 80.0 & 13.1 & .135 \\
\hline & & $40 \mathrm{~s}$ & 79.7 & 23.2 & 73.6 & 18.8 & .065 \\
\hline & & $50 \mathrm{~s}$ & 79.1 & 12.8 & 75.8 & 11.4 & .112 \\
\hline \multirow{8}{*}{$\begin{array}{c}\text { Coping style } \\
\text { (score) }\end{array}$} & \multirow{4}{*}{ Control } & $20 \mathrm{~s}$ & 49.7 & 3.1 & 46.3 & 2.9 & .267 \\
\hline & & $30 \mathrm{~s}$ & 49.5 & 4.8 & 48.6 & 3.01 & .353 \\
\hline & & $40 \mathrm{~s}$ & 51.2 & 5.6 & 49.8 & 5.3 & .215 \\
\hline & & $50 \mathrm{~s}$ & 53.0 & 8.0 & 52.6 & 6.2 & .693 \\
\hline & \multirow{4}{*}{ Experimental } & $20 \mathrm{~s}$ & 49.7 & 1.2 & 49.3 & 7.23 & .939 \\
\hline & & $30 \mathrm{~s}$ & 52.0 & 5.0 & 53.2 & 5.4 & .410 \\
\hline & & $40 \mathrm{~s}$ & 50.3 & 4.1 & 52.9 & 4.6 & $.009^{*}$ \\
\hline & & $50 \mathrm{~s}$ & 52.0 & 8.3 & 51.5 & 7.9 & .668 \\
\hline
\end{tabular}

${ }^{*} p<.05$ by paired t-test.

a change from $80.0(\mathrm{SD}=14.7)$ to $80.7(\mathrm{SD}=14.3 ; p=.184)$, $30 \mathrm{~s}$ from $82.6(\mathrm{SD}=12.1)$ to $90.5(\mathrm{SD}=7.5 ; p=.016)$, $40 \mathrm{~s}$ from $90.9(\mathrm{SD}=10.2)$ to $97.8(\mathrm{SD}=12.3 ; p=.022)$, and $50 \mathrm{~s}$ from $88.1(\mathrm{SD}=15.1)$ to $89.7(\mathrm{SD}=15.4 ; p=.703)$, all showing higher scores after the program. On the other hand, in the experimental group, 20s showed a change from $75.0(\mathrm{SD}=2.6)$ to $62.7(\mathrm{SD}=6.7 ; p=.129), 30 \mathrm{~s}$ from $87.2(\mathrm{SD}=15.1)$ to $80.0(\mathrm{SD}=13.1 ; p=.135), 40 \mathrm{~s}$ from $79.7(\mathrm{SD}=23.2)$ to $73.6(\mathrm{SD}=18.8 ; p=.065)$, and $50 \mathrm{~s}$ from $79.1(\mathrm{SD}=12.8)$ to $75.8(\mathrm{SD}=11.4 ; p=.112)$, all showing lower scores after the program, but without significance.

For stress coping style in the control group, the score of $20 \mathrm{~s}$ was from $49.7(\mathrm{SD}=3.1)$ to $46.3(\mathrm{SD}=2.9 ; p=.267)$, 30 s from $49.5(\mathrm{SD}=4.8)$ to $48.6(\mathrm{SD}=3.0 ; p=.353)$, 40 s from $51.2(\mathrm{SD}=5.6)$ to $49.8(\mathrm{SD}=5.3 ; p=.215)$, and $50 \mathrm{~s}$ from $53.0(\mathrm{SD}=8.0)$ to $52.6(\mathrm{SD}=6.2 ; p=.693)$, showing no significant change. On the other hand, in the experimental group, there was no significant change in $20 \mathrm{~s}$ from $49.7(\mathrm{SD}=1.2)$ to $49.3(\mathrm{SD}=7.2 ; p=.939)$, 30s from $52.0(\mathrm{SD}=5.0)$ to $53.2(\mathrm{SD}=5.4 ; p=.410)$, and $50 \mathrm{~s}$ from $52.0(\mathrm{SD}=8.3)$ to $51.5(\mathrm{SD}=7.9 ; p=.668)$, but there was a significant increase in $40 \mathrm{~s}$ from $50.3(\mathrm{SD}=4.1)$ to $52.9(\mathrm{SD}=4.6 ; p=.009$; Table 6$)$.

\section{Changes by police rank}

We classified the means before Session 1 and after Session 6 by police rank. The ranks of police officers who participated in this study were categorized into constable, corporal, sergeant, lieutenant, inspector, and superintendent. There were no superintendents in the control group, but only one in the experimental group that participated in the program, and thus excluded from the changes by rank. Accordingly, changes in the means were analyzed using five ranks. As for job stress in the control group, constables showed an increase from $77.0(\mathrm{SD}=13.4)$ to $83.3(\mathrm{SD}=12.8$; $p=.345)$, corporals from $72.5(\mathrm{SD}=6.6)$ to $86.3(\mathrm{SD}=9.2$; $p=.108)$, sergeants from $92.9(\mathrm{SD}=10.0)$ to $98.9(\mathrm{SD}=11.5$; $p=.040)$, lieutenants from $88.0(\mathrm{SD}=13.4)$ to 92.2 $(\mathrm{SD}=12.8 ; p=.115)$, and inspectors from $88.6(\mathrm{SD}=8.3)$ to 88.4 ( $\mathrm{SD}=14.3 ; p=.982$ ), all showing higher scores after the program. On the other hand, as for job stress in the experimental group, constables showed a decrease from $77.2(\mathrm{SD}=5.3)$ to $72.6(\mathrm{SD}=15.6 ; p=.548)$, corporals from 
$89.4(\mathrm{SD}=16.4)$ to $79.4(\mathrm{SD}=13.8 ; p=.080)$, sergeants from $89.6(\mathrm{SD}=14.9)$ to $78.9(\mathrm{SD}=18.1 ; p=.059)$, lieutenants from $76.2(\mathrm{SD}=20.2)$ to $73.4(\mathrm{SD}=16.0$; $p=.293)$, and inspectors from $76.1(\mathrm{SD}=18.2)$ to 71.1 $(\mathrm{SD}=13.3 ; p=.101)$, all showing lower scores after the program, but without significance.

For stress coping style in the control group, constables showed a decrease from $48.0(\mathrm{SD}=4.2)$ to $46.8(\mathrm{SD}=2.5$; $p=.663)$, corporals from $50.3(\mathrm{SD}=7.0)$ to $47.8(\mathrm{SD}=4.6$; $p=.155)$, sergeants from $51.8(\mathrm{SD}=5.2)$ to $50.7(\mathrm{SD}=4.5$; $p=.232)$, lieutenants from $50.8(\mathrm{SD}=6.7)$ to $49.9(\mathrm{SD}=5.4$; $p=.360)$, and inspectors from $54.0(\mathrm{SD}=6.7)$ to 53.6 $(\mathrm{SD}=6.4 ; p=.648)$, all showing lower scores after the program. On the other hand, as for stress coping style of the experimental group, there was no significant change in constables from $50.0(\mathrm{SD}=4.0)$ to $52.6(\mathrm{SD}=8.2$; $p=.403)$, corporals from $53.4(\mathrm{SD}=3.9)$ to $54.1(\mathrm{SD}=5.1$; $p=.727)$, lieutenants from $51.2(\mathrm{SD}=4.0)$ to $51.8(\mathrm{SD}=4.4$; $p=.396)$, and inspectors from $50.9(\mathrm{SD}=12.4)$ to 50.4 $(\mathrm{SD}=11.0 ; p=.833)$, but there was a significant increase in sergeants from $49.0(\mathrm{SD}=3.7)$ to $52.5(\mathrm{SD}=3.6$; $p=.017$; Table 7).

In this study, 50 flowers in each of red, orange, yellow, green, blue and purple were decorated every week and delivered to the police station on Monday morning. We explained the symbolic meanings of the names and colors of the flowers when delivering them, and had short conversations to receive feedback on the shapes and scents of flowers. Most police officers were exhausted after the weekend, but they greeted us with bright smiles when we entered the office in the morning with flowers. They also shared certain incidents or stories related to spending the week with the flowers. According to the statistical report of the Korea Employment Information Service (www.keis.or.kr) in 2013, police officers are the most stressed occupation in Korea. This research was conducted during the time when the sub-

Table 7. Changes in the level of job stress and coping style before and after program by police rank

\begin{tabular}{|c|c|c|c|c|c|c|c|}
\hline \multirow{2}{*}{ Item } & \multirow{2}{*}{ Group } & \multirow{2}{*}{ Police rank } & \multicolumn{2}{|c|}{ Before } & \multicolumn{2}{|c|}{ After } & \multirow{2}{*}{$p$} \\
\hline & & & $M$ & SD & M & $\mathrm{SD}$ & \\
\hline \multirow{10}{*}{$\begin{array}{l}\text { Job stress } \\
\text { (score) }\end{array}$} & \multirow{5}{*}{ Control } & Constable & 77.0 & 13.4 & 83.3 & 13.8 & .345 \\
\hline & & Corporal & 72.5 & 6.6 & 86.3 & 9.2 & .108 \\
\hline & & Sergeant & 92.9 & 10.0 & 98.9 & 11.5 & $.040^{*}$ \\
\hline & & Lieutenant & 88.0 & 13.4 & 92.2 & 12.8 & .115 \\
\hline & & Inspector & 88.6 & 8.3 & 88.4 & 14.3 & .982 \\
\hline & \multirow{5}{*}{ Experimental } & Constable & 77.2 & 5.3 & 72.6 & 15.6 & .548 \\
\hline & & Corporal & 89.4 & 16.4 & 79.4 & 13.8 & .080 \\
\hline & & Sergeant & 89.6 & 14.9 & 78.9 & 18.1 & .059 \\
\hline & & Lieutenant & 76.2 & 20.2 & 73.4 & 16.0 & .293 \\
\hline & & Inspector & 76.1 & 18.2 & 71.1 & 13.3 & .101 \\
\hline \multirow{10}{*}{$\begin{array}{c}\text { Coping style } \\
\text { (score) }\end{array}$} & \multirow{10}{*}{ Experimental } & Constable & 48.0 & 4.2 & 46.8 & 2.5 & .663 \\
\hline & & Corporal & 50.3 & 7.0 & 47.8 & 4.6 & .155 \\
\hline & & Sergeant & 51.8 & 5.2 & 50.7 & 4.5 & .232 \\
\hline & & Lieutenant & 50.8 & 6.7 & 49.9 & 5.4 & .360 \\
\hline & & Inspector & 54.0 & 6.7 & 53.6 & 6.4 & .648 \\
\hline & & Constable & 50.0 & 4.0 & 52.6 & 8.2 & .403 \\
\hline & & Corporal & 53.4 & 3.9 & 54.1 & 5.1 & .727 \\
\hline & & Sergeant & 49.0 & 3.7 & 52.5 & 3.6 & $.017^{*}$ \\
\hline & & Lieutenant & 51.2 & 4.0 & 51.8 & 4.0 & .396 \\
\hline & & Inspector & 50.9 & 12.4 & 50.4 & 11.0 & .833 \\
\hline
\end{tabular}

${ }^{*} p<.05$ by paired t-test. 
jects had heavy workload due to the first-half year business report, along with the burden of Ulchi training, but job stress of the experimental group decreased remarkably. There was a study in Japan that had male office workers look at their favorite rose, and even this small stimulation reinforced the parasympathetic nervous system and significantly reduced stress (Ikei et al., 2014). Thus result is in line with the research that conducted eight sessions of horticultural activities on elementary school teachers and discovered that job stress decreased significantly. As a result of having the teachers continuously manage the outputs they worked on in Session 8 without new horticultural activities 4 weeks after the program, job stress also significantly decreased (Choi et al., 2015). Moreover, flower decorations are known to improve emotion regulation ability and reduce depression (Yun et al., 2002), and horticultural activities help psychological welfare of the elderly in institutions (Barnicle and Midden, 2003). Humans can relieve their stress by encountering plants and obtain positive results in terms of mental physiology (Nakamura and Fujii, 1992).

\section{Conclusion}

This study was conducted to determine the effects of the "one-table one-flower" program in an office space on job stress and stress copying style of police officers. We first determined the psychological symbols of colors and selected and decorated flowers in colors that can relieve stress. Then we delivered them to the police station every Monday morning and had the subjects in the experimental group place the flowers on their office desks and look after them. After six sessions of the program, there was a significant difference in job stress $(p<.001)$ and stress copying style $(p=.049)$ of the experimental group compared to the control group. In particular, male subjects showed a significant decrease in job stress, and subjects in their 40s showed a significant increase in stress coping style. By rank, sergeants showed a significant increase in stress coping style. The group showing more active response tended to be more effective. Adopting natural elements in an office environment brings energy into the desolate of- fice, creates a healthy and pleasant environment, and increases work efficiency (Kim, 2001). This study proved that having flower decorations in an office space is effective for psychological stability of police officers that are highly stressed, due to sensory stimulations from the colors and scents of flowers as well as mutual interaction as they take care of the flowers. In particular, looking at and keeping flower decorations nearby is effective in relieving and managing job stress.

The results of this study are limited to only one police station in Daegu, and thus the level of job stress may be different from a police station in the big and crowded city of Seoul or in a quiet, secluded region. Therefore, it would be meaningful to expand the scope of research to police stations nationwide based on the model of organizational health that job stress of police workers must be managed at an organizational level (Yoo, 2014). Furthermore, various effects of flowers can also be determined by the "one-table one-flower" program in other office areas where stress levels are high.

\section{References}

Arter, M.L. 2007. Stress and deviance in policing. Deviant Behav. 29(1):43-69. https://doi.org/10.1080/016396207 01457774

Barnicle, T. and K.S. Midden. 2003. The effects of horticulture activity program on the psychological wellbeing of older people in a long term care facility. HortTechnology 13(1):81-85. https://doi.org/10.21273/ HORTTECH.13.1.0081

Cho, M.K., S.I. Jung, K.C. Son, and M.K. Kim. 2003. Effect of phased application of horticultural therapy programs on improvements of assertiveness and interpersonal relationship of chronic schizophrenia. J. Korean Soc. Hortic. Sci. 44(6):972-979.

Choi, Y.H., S.Y. Yun, and B.J. Choi. 2015. Effects of horticultural activity on job stress, coping ability, and job satisfaction of elementary school teachers. J. Korean Soc. People Plants Environ. 18(4):327-331. https://doi.org/10.11628/ksppe.2015.18.4.327

Folkman, S. and R.S. Lazarus. 1985. If it changes it must 
be a process: Study of emotion and coping during three stages of a college examination. J. Pers. Soc. Psychol. 48(1):150-170.

Gong, S.J. and E.H. Lee. 2006. Mediation effect of coping between life stress and depression in female college students. Korean J. Women Psychol. 11(1):21-40.

Igarashi, M., C. Song, H. Ikei, T. Ohira, and Y. Miyazaki. 2014. Effect of olfactory stimulation by fresh rose flowers on autonomic nervous activity. J. Altern. Complement. Med. 20(9):727-731. https://doi.org/10.1089/acm.2014.0029

Ikei, H., M. Komatsu, C. Song, E. Himoro, and Y. Miyazaki. 2014. The physiological and psychological relaxing effects of viewing rose flowers in office workers. J. Physiol. Anthropol. 33(1):6. https://doi.org/10.1186/1880-6805-33-6

Jeong, H.I. and I.J. Han. 2008. A study on the methodology of analysis for the five senses development of children by flower arrangement. J. Korean Soc. Flor. Art Des. 18:89-118.

Jeong, Y.S. and J.M. Yoon. 2014. A study of job stress among Korean police officers and their coping strategies. Mod. Soc. Public Adm. 24(3):25-55.

Katakiri, Y. 1996. Flower remedies. Seoul, Korea: The Press Jongienara.

Kim, H.Y. 2003. Horticultural therapy theory and practice. Daegu, Korea: Korean Horticultural Therapy Research Center.

Kim, J.S. and S.H. Kim. 2011. Design and implementation of a customized contents service system for relieving users' stress. J. Korea Contents Assoc. 11(2):101-112. https://doi.org/10.5392/JKCA.2011.11.2.101

Kim, K.J., M.J. Kil, H.D. Kim, J.S. Song, E.H. Yoo, J.G. Cho, S.J. Jeong, K.J. Na, and E.B. Jeung. 2006. The effect of flower scent and essential oils on reduction of concentration of Cortisol, a stress hormone. Korean J. Hortic. Sci. Technol. 24(3):417-424.

Kim, K.N. 2001. A study of environmentally-friendly characteristics from office environment to atrium. Master's thesis, Konkuk University, Seoul, Korea.

Kim, S.H. 2013. Color psychology: Color that heals body and mind. Seoul, Korea: The Press Books I \& I.

Kim, S.Y., C.T. Koo, and K.C. Yoon. 2002. Stress level police officer's job stress: The degree and determinants of job stress. Korean J. Public Adm. [Seoul National University] 40(1):123-147.

Kim, Y.O. 2014. The relations between job stress and depression of woman police officers: focusing on the moderating effect of stress-coping, social-support, self-esteem. Master's thesis, Jeju University, Jeju, Korea.

Moon, Y.S. 2011. The level and influencing factors of police officers' job stress. Korean J. Local Gov. Stud. 14(4):41-60.

Nakamura, R. and E. Fujii. 1992. A comparative study on the characteristics of electroenphalogram inspecting a hedge and a concrete block fence. J. Jpn. Inst. Landsc. Archit. 55(5):139-144.

Simson, S. and M.C. Straus (Eds.). 1997. Horticulture as therapy: Principles and practice. Binghamton, NY: The food products press.

Son, K.C. 1997. Horticultural therapy. Seoul, Korea: Chung-Ang Sanghwal Pub.

Spielberger, C.D., L.G. Westbury, K.S. Grier, and G. Greenfield. 1981. Police stress survey - Sources of stress in law enforcement. Tampa, FL: Human Resources Institute, University of South Florida.

Tak, S.H. 2006. An insider perspective of daily stress and coping in elders with arthritis. Orthop. Nurs. 25(2):127-132.

Ulrich, R.S. 1981. Natural versus urban scenes: Some psychophysiological effects. Environ. Behav. 13(5):523-556. https://doi.org/10.1177/0013916581135001

Yoo, J.C. 2014. The effect of the job stress of the police on the job attitude: Comparing security police and auxiliary police in Seoul police agency. J. Police Sci. [Korea National Police University] 14(2):105-137.

Yun, S.Y., B.J. Choi, and H.Y. Kim. 2009. The effect of flower arrangement on the balance of feelings and depression of hospitalized elders. J. Korean Soc. People Plants Environ. 12(6):1-5.

Yun, S.Y., H.Y. Kim, M.K. Cho, and T.Y. U. 2002. Research preference of flowers and effect of floral decoration on the improvement of recognition ability in the demented old adults. J. Korean Flower Res. Soc. 10(1):41-46. 